\title{
LAS COMARCAS TAMBIÉN TIENEN HISTORIA, SAN ANTONIO SUR, CONTRASTE URBANO-RURAL
}

Alejandra Rebecca Pérez López

\section{Resumen:}

En este artículo se escribe la bistoria de la comarca San Antonio Sur, rescatando aspectos culturales, formas de vida, problemas sociales, que bacer económico; baciendo un análisis de sus diferentes facetas, características y comportamiento de los babitantes. Analizaremos el fenómeno de poblamiento y expansión, todos estos sujetos a la óptica histórica; Teniendo como principal objetivo fortalecer la identidad local. Respecto a la metodología usada se bace referencia a las fuentes orales como testimonios de las realidades, que viven inmortalizadas en la memoria colectiva de la población de estudio.

Palabras clave: Historia oral, Comarca, identidad.

\begin{abstract}
:
This article shows San Antonio Sur's bistory, rescuing culture aspects, ways of life, social problematic, economical activities; providing an analysis of its different views, characteristics and local population behavior. We're going to analyze the settlement and expansion topic, from bistoric posture; baving as a principal objective reinforces the local identity. About the method used it refers to oral sources as a testimony of realities, which are immortalized in collective memory.
\end{abstract}

Keywords: Thought, thinking problem, ex-colonies, recipients of thought.

Antes de la escritura misma ya existía la oralidad, es decir, la transmisión de los conocimientos de una generación a otra por medio del discurso. En antiguas formaciones sociales, las personas de mayor edad eran las depositarias del saber sustentadas en la acumulación de las vivencias y los encargados de su transmisión a las nuevas generaciones con el fin de preservar la cohesión cultural de estos grupos humanos. En sociedades africanas, cuando un anciano moría se decía que ardía una biblioteca o como dijo nuestro recién fallecido Eduardo Galeano (Lunes 22 de noviembre de 2010) en memorias y desmemorias (Galeano, 2010)“ La memoria viva no nació para ancla, tiene más vocación de catapulta"

Sabemos que la creación de la escritura y posteriormente la invención de la imprenta (siglo XV), han sido los vehículos por medio del cual la especie humana se ha auxiliado para modelar las diversas visiones del mundo con que contamos hoy día, permeando en gran medida el imaginario de muchas generaciones, durante siglos. Esta condición contenedora de memoria histórica y colectiva (Halbwachs, 2004) sustentada en la cultura impresa, hace que los grandes acontecimientos, los hombres considerados notables por sus aportes en el desarrollo de la sociedad, las epopeyas, guerras, desastres, lasestructuras políticas y socialescreadas para regular la vida de los colectivos humanos, sean una suerte de bendición para muchos.
Una pregunta que desde el siglo pasado $(X X)$ se viene haciendo el estudioso de la historia y la cultura de los diferentes grupos humanos, es iqué pasa con la historia o las vivencias de los de abajo, los grupos subalternos? ¿Son pueblos sin historia? La dificultad que encaran los especialistas o historiadores (en los cuales me incluyo) es la carencia o dispersión de fuentes que contribuyan al rescate o esclarecimiento de hechos del pasado, lejano o reciente, de sectores subalternos, grupos sociales marginales, habitantes de un espacio geográfico y sus luchas por su supervivencia o reconocimiento por el poder central, Este intersticio documental ha sido llenado por lo que en los últimos años se conoce como Historia Oral.

En el actual siglo XXI que recién ha iniciado, los centros urbanos, su cultura e historia han adquirido una enorme importancia en detrimento de las zonas rurales, que como en nuestros países, siguen teniendo preeminencia en la vida diaria de amplios sectores sociales nicaragüense, sus representaciones y prácticas discursivas. Este trabajo tiene como finalidad la de construir la historia de la Comarca San Antonio Sur, una comunidad rural ubicada al suroeste de la capital, la cual por el mismo crecimiento acelerado de la ciudad hacia esta zona, empieza a sufrir importantes trasformaciones, no sólo desde el punto de vista de la infraestructura, sino en la vida cotidiana, en la conformación de sus habitantes. 
Este "peligro modernizador", es uno de los alicientes de este trabajo, que busca estructurar la historia de esta comunidad, en apariencia de poca importancia pero que como todo conglomerado social, tiene su rostro, su memoria y su historia, la cual forma parte de una región y de un discurso histórico de Managua.

La centralidad inicial de la investigación, busca ubicar los aspectos importantes que contribuyeron a la configuración de esta comunidad hasta llegar a ser reconocida como "comarca", sabiendo que esta definición tiene un sustento político-administrativodado por el Estado. Este macro criterio, permitirá adentrarse en los hechos o intereses propios de la comunidad, que desde el punto de vista histórico, les reconocieron para llegar a ser comarca. La reconstrucción de la vida cotidiana, de sus pobladores, su imaginario colectivo, es otro elemento a rescatar con el fin de establecer ese nexo entre la vida rural, reconocida por su condición de "comarca" y el "amenazante" mundo urbano el cual toca en la actualidad sus puertas, abriendo otro capítulo en su historia.

Como señala Bendiba (2007) en relación a los procesos de construcción histórica, estas se dan cuando se tiene una percepción clara de su propia historicidad e identidad, lo cual le permite-continua el autor--actuar y proyectarse con certeza y efectivamente en la sociedad que viven (pág71).

\section{Metodología}

Esta se basará en los enfoques de historia oral, como el principal sustento de información. Para ello, se realizaron una serie de entrevistas, tanto biográficas como temáticas, garantizando durante su proceso, la objetividad e imparcialidad informativa requerida. En este sentido, el establecimiento de comparaciones (confrontaciones o contrastes) de los testimonios, es de gran importancia para el estudio, en especial para apropiarse de los diferentes puntos de vista o aspectos que se pretenden destacar, según nuestros propósitos planteados en la introducción.

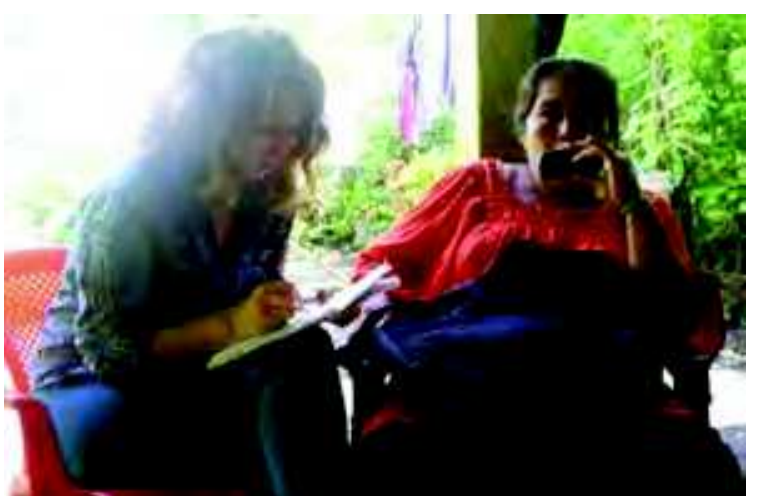

Foto 1. Entrevista realizada a Ruth López. Fuente Blanca López, 2014.
La selección de las personas entrevistadas se hizo bajo un proceso lógico, donde se tomaron en cuenta personajes populares o de gran arraigo, influencia o respeto moral dentro de la comunidad. Entre ellos se incluyeron,maestras, ancianos,amas de casa, agricultores y delegados de la palabra. Este ejercicio permitió la estructuración de una red de contactos que ayudaron al completamiento de la información requerida para el estudio.

También se hizo uso de las fuentes fotográficas como evidencia de las problemáticas vividas en la comunidad. En este caso, la selección y análisis de los contenidos iconográficos fue un sustento fundamental que complemente la construcción testimonial y discursiva de la evolución de la comarca, al incorporar imágenes representativas de la infraestructura y de la cultura.

El estudio local no sería posible sin el auxilio teórico de las fuentes documentales. La ubicación de referencias documentales o bibliográficas relacionadas con la comarca y con el municipio histórico de Managua, es otro ejercicio metodológico implementado, al analizarse por medio de contraste o verificación de información dada por diversos autores, de la conformación, ubicación y poblamiento de San Antonio Sur.

\section{El que lo vio y quien lo vivió}

La comarca San Antonio Sur, es una comunidad rural, ubicada en el municipio de Managua, departamento de Managua. Limita al oeste con el municipio de El Crucero, al noroeste con la comarca Santo Domingo, al este con la comunidad de los Escobares y alsur con la comarca Gaspar García Laviana. Forma parte de la subcuenca III del lago de Managua,cuya depresión fue causada, según Pablo Emilio Barreto (2010), por el aluvión de 1876,considerado como uno de los desastres naturales más trágicos del país.

En sus inicios,San Antonio Sur era un pequeño caserío en donde unas cuantas familias se asentaron. Era una comunidad aislada, por la ausencia decaminos, su acceso o contacto con otras comarcas o poblados, se daba por medio de pequeñas veredas improvisadas utilizadas por los nuevos colonos que iban habitando el lugar.

Según información recabada, las primeras familias que poblaron lo que hoy es San Antonio Sur, son anteriores al aluvión de 1876. Dos de esas familias recordada por sus habitantes, son identificados por los apellido Ayerdis y Suárez, quienes ven divida sus tierras a causa de la tragedia natural conocida como "aluvión de 1876": "Lo que pasa es que el aluvión según mi mamita, rompe todo esto, porque aquí todo esto era unido a lo de los Suarez, y entonces se hizo el camino y empezaron aquellos a decir que el camino 
era de ellos"(Sotelo, 2014). Según el periodista y cronista Pablo Emilio Barreto,el desastre natural conocido como "el aluvión", fue producto de un temporal que azotó la zona sur de Managua, en octubre de 1876, causando deslizamiento de tierra y avalanchas de lodo, piedra y maleza proveniente de la cordillera de los pueblos. Este hecho documentado históricamente, por otros cronista que vivieron cerca de esa época, como Don Gratus Haltermayer(2008) y Eliodoro Cuadra (1939), afectó también el casco urbano de Managua. Demostrando con ello que los deslizamientos de tierra de esa época se dieron en diferentes puntos del municipio de Managua.

Como se ha señalado, la depresión surgida producto del aluvión, creó las condiciones para el asentamiento de más familias, pues este fenómeno natural, creó una brecha que permitió el acceso menos accidentado al lugar y provocando a la vez, una re distribución de tierras. Como secuela de esta tragedia natural, esta comunidad es bautizada por sus pobladores y resto de habitantes aledaños, como El arroyo. La referencia a este acontecimiento histórico-climático sugiere, que esta comarca en estudio es de reciente fundación.

Según testimonios recopilados, a finales del siglo XIX e inicios del XX, se da una nueva una nueva "oleada" de familias que se asientan en la comunidad El arroyo (hoy San Antonio Sur), cuyos apellidos se identifican como Lola, Porras, Garay entre otros. Estas familias, se les recuerda, por haber introducido en la comunidad, prácticas agrícolas distintas a la de sus originarios habitantes, acostumbrados al cultivo de árboles frutales, en particular granos básicos para el consumo, cuyo excedente es utilizado para su comercialización.

En la década del 60 del siglo pasado, la comunidad El arroyo comienza a conocerse como comarca San Antonio Sur, como producto de contingencias de políticas públicas. Para esta fecha, se inaugura la escuela rural de primaria, bautizada con el nombre de San Antonio, sobre el camino real al crucero. En poco tiempo, la escuela se convierte, en punto de reunión de la comunidad,y en un referente geográfico para sus habitantes y resto de comunidades aledañas que comienzan a utilizar este nombre como ubicación y como parte de su identidad colectiva.

Hasta mediados del siglo XX, La comunidad de San Antonio Sur, estaba conformado por propiedades de medianas extensiones, pertenecientes a funcionarios vinculados al régimen somocista. Entre estos personajes cabe destacar al Coronel Samuel Genie, de tristes recuerdos para muchos, en la etapa final del gobierno de "Tachito", al ser parte de la máquina represora contra el pueblo. Otro mediano propietario fue Oscar Lola, y Arturo Cruz Porras, este último se le recuerda por su personalidad afable, simpático y estimado por los vecinos, y quien desde su posición de funcionario influyente (fue Ministro del Distrito Nacional) a finales de la década del 60 , gestionó mejoras materiales para la comunidad, como la construcción de la escuela primaria,bautizada como San Antonio Sur, nombre que desplazaría al anterior "El arroyo" y con el cual se le conoce hasta hoy día a la Comarca.

Según el señor Noel Fonseca miembro de la comunidad, el Ministro Cruz Porras habitaba frente a la escuela. Era propietario de un molinode cereales y un cine, recordado con mucha nostalgia por las amigas de juventud doña Ruth López Y doña Dora Ayerdis por $\quad \begin{aligned} & \text { Foto 2. Ministro del Distrito Nacional, } \\ & \text { Arturo Cruz Porras. Fuente www.manfut.org. }\end{aligned}$ sus divertidas películas de origen mexicanaexhibidas de manera periódica y que reunía a la mayor parte de sus habitantes durante esas horas. También, el señor Cruz Porra, era propietario de uno de los dos pozos existentes en la comunidad, el cual contribuía al abastecimiento de agua delos hogares de San Antonio Sur. El control del agua le aseguraba a este personaje una posición de poder e influencia en la comarca.

\section{Sin electricidad pero con cine}

Como se ha señalado, en la segunda mitad de la década del 60 a la comarca se empieza a conocer con el nuevo nombre de San Antonio Sur, dado por la escuela recién construida. En la comunidad se carecía de los servicios básicos indispensable para vivir mínimamente con dignidad, al carecerse de agua potable y luz eléctrica. Lejano estaba el pensar que la comunidad contara con servicio telefónico. Además del pozo construido por Don Cruz Porras, existía otro perteneciente a un cercano colaborador de régimen somocista, identificado como "oreja" (delator) de apellido Garay, ambos comerciaban el agua, cuyo precio por barril, para esa época era de un córdoba, precio nada económico para los bolsillos de los consumidores.

El drama vivido por sus habitantes en esa época, para abastecerse de agua, es recordado por los vecinos de la comunidad, con una mezcla de añoranza por un pasado que no volverá y el alivio de saber que 
esa situación fue superada. Cuentan que los barriles después de llenados en los pozos privados, eran trasladados a las viviendas en carretones de mano o halados en carretas por bueyes. Según doña Ruth López, "el barril de agua lo vendían a peso y si lo traían a domicilio diez, porque no todos tenían carretones..." (López 15 de sep. 2015).

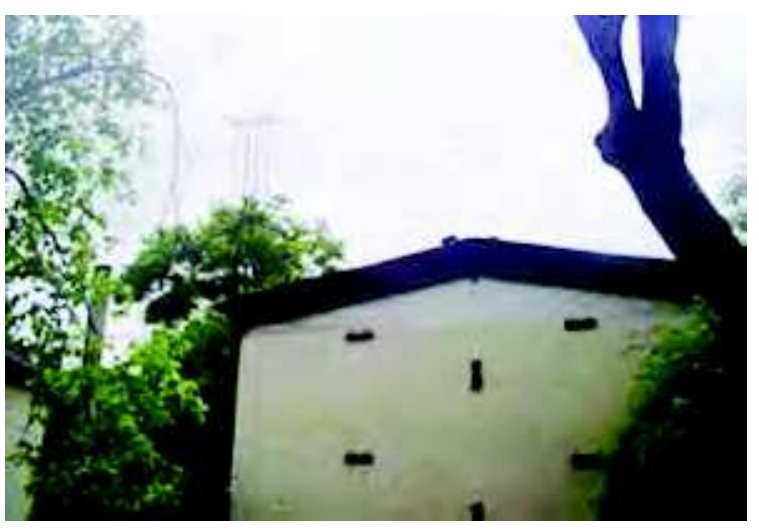

Foto 3. Antiguo sitio del pozo y cine. Fuente propia, 2014

En el año de 1978 la comunidad es beneficiada con la construcción de un pozo comunitario excavado en los terrenos de la familia Díaz Aburto, sin embargo, el cambio el cambio esperado con esta obra estatal, no tuvo el efecto esperado de alivio, por la deficiencia en el servicio, según los Catalina Fue con el gobierno revolucionario (1979-90) que el pozo se conecta a la red de agua potable administrada por ENACAL, ya para esa época, la población se había incrementado y las demandas iban en aumento.

En relación al servicio eléctrico, los informantes entrevistas, recuerdan que para la década del 60 existían algunas casas con este servicio, como la de don Cruz Porras, quien por su posición económica e influencia política era un privilegiado. El contar con el servicio de luz eléctrica, por medio de planta personal, le permitió a este señor, abrir y administrar un espacio para la proyección de películas. Por otra parte, la mayoría de sus habitantes recurrían a candiles de kerossine, o lámparas de gas (Coleman) o candelas para alumbrarse por la noche. El planchado lo hacían con planchas de hierro, calentadas con brasas de carbón.

En cuanto al uso de transporte colectivo, en la comunidad, la familia Estrada era propietaria de un autobús, que cubría la ruta del kilómetro 10 1/2 de la carretera hacia Masaya, San Antonio hasta llegar a las cuatro esquinas en Ticuantepe. Don Julio Estrada era el que hacía la ruta por caminos rurales, la mayoría de ellos, creados por las lluvias, siendo cauces naturales que forman parte de la subcuenca III, razón por la cual la travesía en este autobús era dura, haciendo que el servicio no fuera de buena calidad.

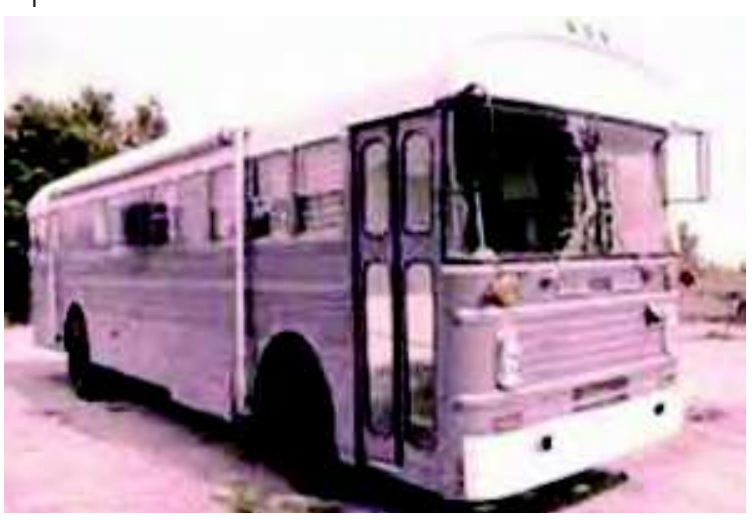

Foto 4. Primer bus usado en la comarca. Fuente propia, 2014.

\section{Factor económico}

Por su naturaleza rural, las actividades económicas a la que se ha dedicado la comunidad, por mucho tiempo, ha sido el cultivo de algunos productos agrícolas, los cuales hasta hoy día se siguen cultivando. Es importante destacar algo que ya se ha mencionado, y son los cambios introducidos en términos de manejo de tierra e introducción de nuevos cultivos por vecinos, que en diferentes épocas han llegado asentarse a San Antonio Sur.

En la comunidad ha existido diversos tipo de propiedad de tierra, la mayoría eran pequeños propietarios (1/2 a 6 manzanas) y unos pocos medianos propietarios, dedicados al cultivo de plátano, piña, cítricos, hortalizasy frutales, entre ellos, mango, tamarindo, jocote comercializados en el mercado central o San Miguel (antes del terremoto de 72 que destruyó Managua) y Oriental después. La familia que concentraba la mayor cantidad de tierras en la comunidad, era la familia Porra quien cultivaba la mayor parte de estos productos. Este señor Porras, posiblemente con parentesco con Cruz Porras, era también propietario de la tienda (pulpería) más grande de la comarca, donde sus habitantes podía encontrar productos de primera necesidad, sin tener que ir a los pueblos cercanos o la capital para adquirirlos.

Otros propietarios fuertes del lugar, eran las pertenecientes a las familias López y Fonseca, esta última dueña de varias hectáreas de tierra donde cultivaban plátano.No obstante, la piña era (y continúa siendo) uno de los rubros más cultivado. Según la entrevistada Catalina Silva "Todo esto eran piñales, los Fonseca sembraban plátano, y tu abuelita sacaba el tamarindo" (15 sep. 2014). 


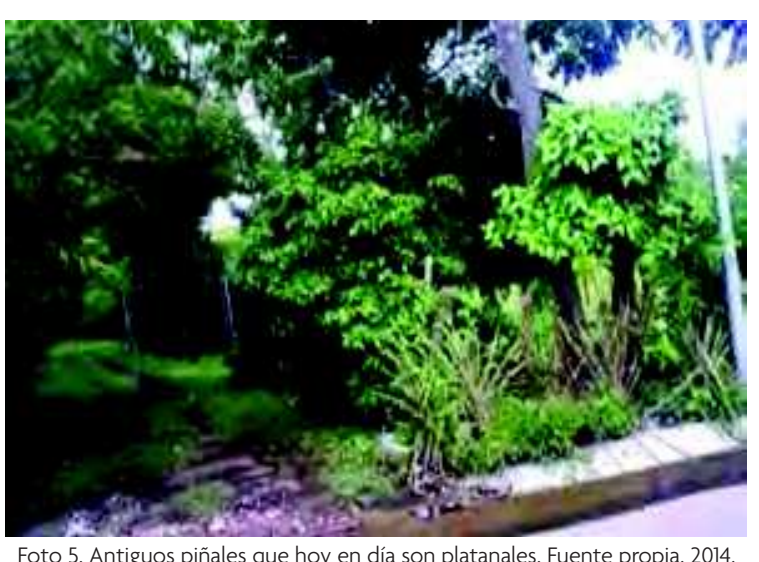

Foto 5. Antiguos piñales que hoy en día son platanales. Fuente propia, 2014

Otra de las actividades económicas a la que se dedicaban era la crianza de animales de granja, como cerdos, ganado vacuno y aves de corral. Una de las familias que se dedicaba a la crianza y comercialización de carne y leche de vaca, era la familia López, dueña de la finca Las Llaves, ubicada en el camino a Las Cuchillas (La Miona).

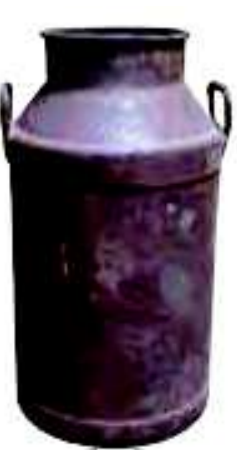

En estas actividades participaban hombres y mujeres, cultivando y participando en la comercialización de la cosecha. Aunque es importante destacar que la mujer tenía un rol adicional, dentro de una cultura patriarcal, acendrada, como era las labores doméstica, el cuido y la educación de los hijos.

Foto 6. Recipiente usado para guardar leche. Fuente propia, 2014

\section{Aspectos sociales}

\section{Cambios en la tenencia de tierra}

Como se ha mencionado en este trabajo,algunas familias simpatizantes con el régimen dictatorial de los Somoza eran dueñas de pequeñas y medianas propiedades, las cuales con la revolución de 1979 se verían afectadas con las leyes implementadas por el nuevo régimen. Según el testimonio de Dorita Ayerdis,loshabitantesde la comunidadrecibieron sus lotes de terrenos, donde construir sus casas, gracias al apoyo del ministro Cruz Porras:

... las tierras se dividieron y esta parte de esquina a esquina, le pertenecía a los Suárez, antes no había división de terrenos. Por gestión de don Arturo Cruz Porras, se distribuyeron estas tierras, en pequeños solares, dándole a vivir a la gente. Nosotros fuimos beneficiados por medio de mi abuelita.(Ayerdis 16 sep. 2014).
Después del triunfo de la Revolución Popular Sandinista, los propietarios que tuvieron vínculos con la recién dictadura derrocada, fueron expropiados y algunas tierras confiscadas. Otras fuerontomadas por los habitantes, en particular por aquellos que fungieron como vigilantes, tal es el caso de don Benigno Altamirano, cuidador de una propiedad de un guardia nacional de nombre Byron.

\section{Educación}

Desde mediados de la década de los 60, la comunidad contaba únicamente con la escuela primaria San Antonio Sur, pequeña establecimiento educativo, donde se impartían dos grados en una misma aula (era una especie de multigrado) . Los materiales que conformaban su infraestructura, era mitad de madera y mitad debloque (popularmente le llaman "minifalda) y zinc, constituida por seis aulas y un área para la dirección y administración de la escuela.

En sus inicios,según cuentan los habitantes, los padres le confeccionaban a los hijos cuadernos rústicos de papel de de periódico (conocido popularmente como de "envolver") con una costura en el margen. Al no contar con suficientes recurso para compra mochila, los niños llevaban sus cuadernos y lápices en bolsasde plástico, el uniforme no era exigido pero se dejaba en libertad que el que pudiera llevarlo, que así hicieradoña Dora recuerda con mucha claridad la angustia que les causaba el sonar de la campana, como signo de observar en la disciplina: ...era un pedazo de hierro y le daban con otro y sonaba blanblan, ve...la gente obediencia (Sotelo, 2014).

Gran parte de la educación durante la década de los 60 y 70, en particular la destinada a los sectores pobres y rurales, era financiada por el programa de Alianza Para el Progreso (ALPRO). Muchos recuerdan el emblema de las dos manos de la Alianza, puesta en las pastas de los libros, los sacos de leche en polvo y las latas de aceite que llegaban a las escuelas y hogares. Otros han olvidado que fue el gobierno del Presidente Kennedy quien impulsó esta iniciativa para las Américas en 1962, como reacción al peligro, --según ellos--, que representaba el ejemplo de Cuba para las sociedades latinoamericanas:

La ALPRO pretendía alcanzar una docena de metas durante la llamada década del desarrollo (años sesenta) tendientes a mejorar la calidad de vida de la región"(Gutierres, 2003). 


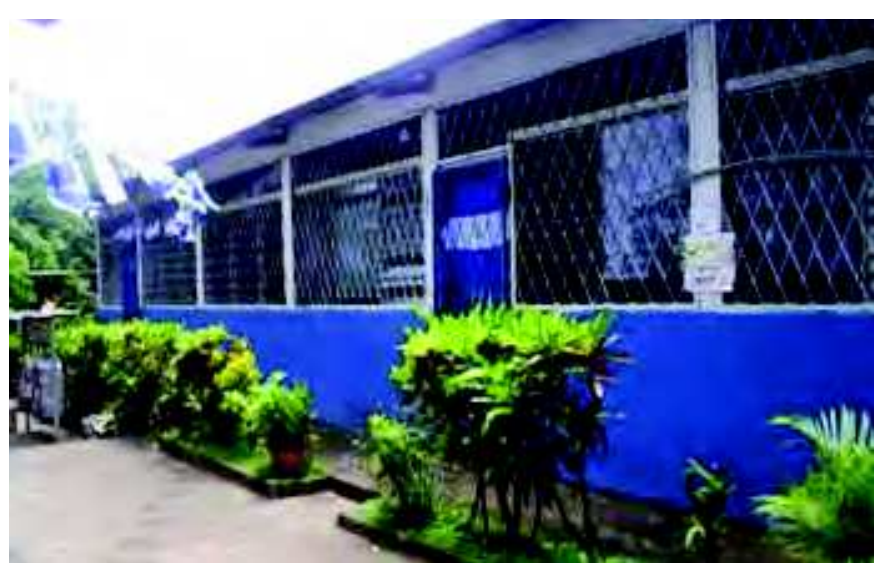

Foto 7. Colegio de San Antonio. Fuente propia, 2014.

En vista que la escuela únicamente ofrecía educación primaria en la comarca, la mayoría de los jóvenes eran inducido u obligados por sus padres a trabajar, frenando la continuidad de la educación. Algunos con iniciativa y deseo de superación, viajaban a Managua, y de manera particular al barrio René Schick, cercano a la comarca y fundado en la década del 60 por el Presidente que le da nombre. Otros "intrépidos", viajaban hasta la Nacional de Comercio o el Instituto Ramírez Goyena. Hasta la década de los 80, pocos jóvenes alcanzaban la universidad, y los que llegaban a secundaría ejercían la docencia en las escuelas públicas. En la actualidad,el sistema educativo permite un acceso fácil a las escuelas, aunque todavía con deficiencias en cuanto a la calidad de la enseñanza.

\section{Infraestructura}

Hasta inicios de la década del 70, los caminosde acceso a la comunidad, era de tierra, accidentado por su origen natural. En esa década el gobierno creó rampas con el fin de aliviar la fluidez del agua pluvial proveniente de las sierras, durante el invierno, mitigando la erosión y las inundaciones de las casas situadas sobre los caminos reales.

Hasta la década de los 90 estos caminos no tuvieron ninguna intervención en función de mejora. A finales del gobierno de ArnoldoAlemán (1997-2000), construyó la carretera que cubre la ruta del km 10 1/2 carretera Masaya, finca de Fabio Gadea, consuegro del Presidente. La informante señora López, recuerda este hecho: Por conveniencia fue construida esa carretera, aprovechándose Alemán de los recursos del Estado para beneficiar a Fabio (López, 2014). Las viviendas de las familias de menores recursos económicos, eran de techo de paja, madera o adobe, con piso de tierra, lo cual contrastaba con las pocas casas de familias con mayor recurso como la del señor Cruz Porra. La señora López recuerda: "donde Alejandra Rebecca Pérez López el Ministro Cruz, ahí era bien bonito, bien bonito el terreno, verdad que tiene más de cien años esa casa...."(López, 2014).
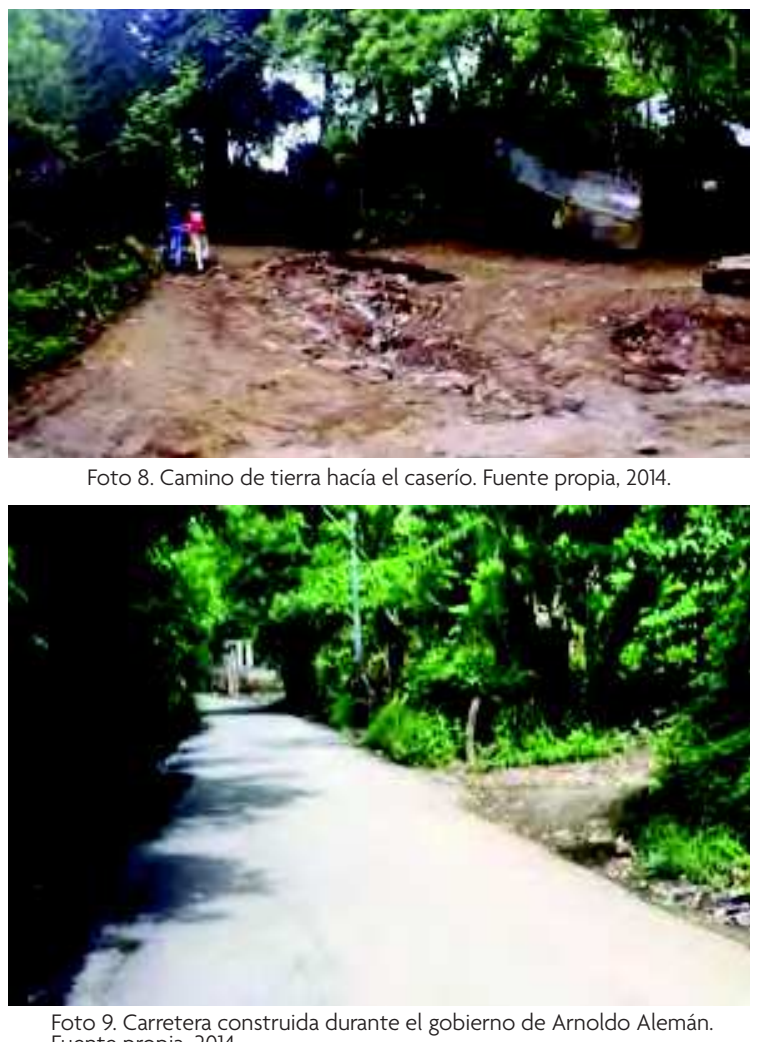

Fuente propia, 2014

Otros edificios que recuerdan los informantes es el cine San Antonio ubicado frente a la escuela, el cual era un edificio cómodo y de buen aspecto. Entre las construcciones lujosas estaba la del coronel Mendieta, piloto de la Guardia Nacional (GN); y el de la familia Lola, cuyo diseño peculiar, de cabaña, parecía un edificio transportado de un país frío, a uno tórrido, tropical.

Espacios de recreación para alumnos de la escuela - para las familias durante los fines de semana, como parques o canchas no existían, teniendo que improvisar en los patios o en los caminos:

“...jugábamos en el camino, el recreo era de donde mi mamita hasta la escuela todo eso era el recreo, casi no habían carros y por eso tranquilo....”(Dora, 2014).

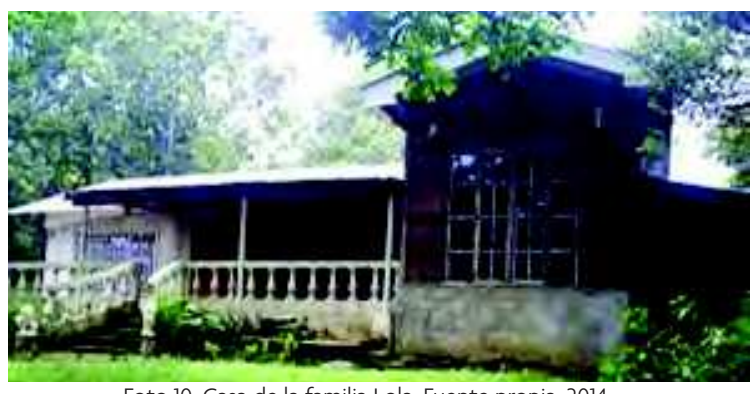

Foto 10. Casa de la familia Lola. Fuente propia, 2014.

Las comarcas también tienen historia, San Antonio Sur... 


\section{Factor político ideológico}

Para la década del 60, la mayoría de la población erasimpatizante del régimen somocista, o al menos se manifestaban como liberales.La algarabía de las campañas políticas, aún cuando muchos sabían que no eran trasparentes, se hacía sentir en toda la comunidad. Los dirigentes partidarios del régimen, enviaban buses expresos a traer a los simpatizantes, a quienes transportaban a los sitios donde se realizarían los mítines.

Todavía algunos recuerdan esas marchas, la explanada de Tiscapa (donde hoy está la plaza Inter) y la plaza de la República (hoy Plaza de la revolución) donde se realizaban las principales concentraciones políticas y se escuchabanlos discursos de Anastasio Somoza Debayle, protegido con una vitrina anti bala. También recuerdan, la repartición de aguardiente y bolis (refresco en bolsa de plástico) como señuelo usado para acarrear a los correligionarios, todos ellos portando retratos de un Somoza sonriente, joven, esbelto, que en la realidad era lo contrario, era un hombre envejecido, ventrudo por el exceso de comida y de bebida: "...Fíjate que antes de la revolución, la mayoría eran de tendencia Somocista y venían aquellos buses a traer gente, y a todo el iba 54 le daban unos bolis con guaro...”('López, 2014).

Producto de la crisis económica y social imperante, profundizada por el terremoto que destruyó la capital en diciembre de 1972, algunos jóvenes de la comarca empiezan a simpatizar e involucrarse en las actividades del Frente Sandinista de Liberación Nacional (FSLN).Los institutos públicos son el lugar donde estos jóvenes toman conciencia de la situación que vive la población bajo el régimen imperante y la necesidad de acabar con una dictadura de más de 40 años. Algunos jóvenes de la comarca fueron protagonistas en las luchas contra la dictadura, a finales de la década del 70.

Después del triunfo de la Revolución Popular Sandinista, los jóvenes de la comarca se incorporaron en la Gran Cruzada Nacional de Alfabetización: ".Yo tenía todo listo ya, mi uniforme y la mochila para ir a la cruzada, pero me dio miedo y no quería dejar sola a mi mama. De aquí de San Antonio fueron casi todos, a los que nos quedamos nos pusieron a aprender defensa civil..."(Dora, 2014).

En la actualidad la mayoría de los habitantes de la comunidad simpatizan con el FSLN. Los planes sociales impulsados por el gobierno como Plan techo, bono productivo, entre otros, ha tenido su impacto en la vida de sus habitantes, y mejorado la percepción que tienen con el partido sandinista. No obstante, algunos pobladores manifiestan inconformidad con el gobierno, por problemas relacionados con proyectos prometidos, los cuales, según su opinión, se han desnaturalizados, como el de los terrenos para construir "casas para el pueblo". Un informante que pidió no poner su nombre, se queja: "Ahora nos están haciendo como en los años ochenta lo tienen disfrazado diplomáticamente, antes lo hicieron abiertamente, ahora diplomáticamente, pero en la misma cosa estamos que en los años ochenta peor y eso es para callarle la trompa a todo mundo dan una cosita un chanchito y es para callarlos."(anónimo, 2014).

\section{Cultura}

En cuanto a la religión, la población en principio era mayoritariamente católica, y al no tener una iglesia en la comunidad se dirigían a la iglesia de Santo Domingo; por ello, hay muchos lazos culturales.Se comparten festejos como el del patrono de Managua, Santo Domingo, celebradas en agosto, y el de la comarca San Antonio, el 13 de junio; en estos se destaca la familia Castañeda por su devoción. Además de ello, hay familiascomo la Artola, que celebran la purísima, en principios regalaban arroz de leche, gofio, caña, entre otros productos que ellos mismos elaboraban.

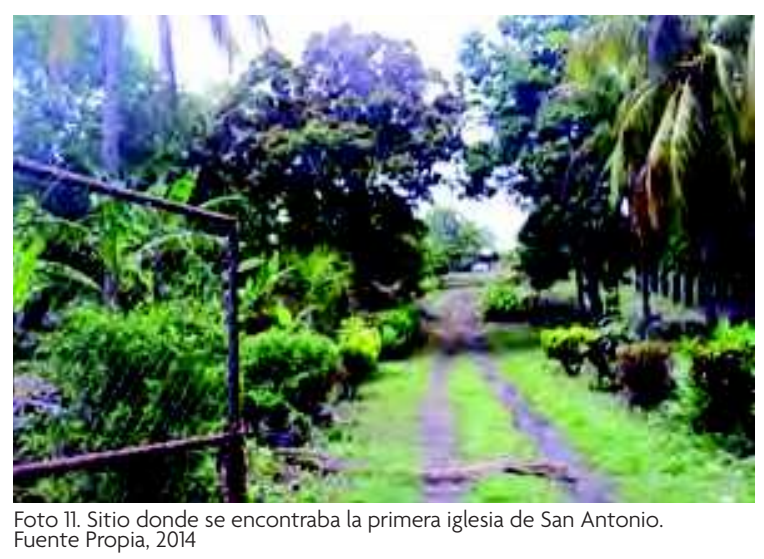

En el año 1971, en la comunidad se construyóla primera iglesiade la rama protestante, de corriente anabaptista y de denominación Hermanos en Cristo;esto trajo como fenómeno el cambio de religión de muchas familias. Este proceso no fue fácil para los primeros protestantes que llegaban a evangelizar. "... Los apedreaban, e incluso hasta la iglesia llegaban a apedrear...”(López, 2014).

\section{Tertulias y recreación}

Otro aspecto que ha contribuido al fortalecimiento 
de la identidad de pertenencia a San Antonio de sus habitantes, son las tertulias que cada tarde se realizaban en cada una de las casas.Luego de las jornadas de trabajo o de los quehaceres de la casa, cada uno de los miembros tenía por costumbre reunirse en las cocinas 0 al frente de la casa a escuchar la radio y conversar sobre temas y problema cotidianos de la comunidad.

Según los entrevistados de mayor edad, las radios que sintonizaban con mayor frecuencia eran la Mundial y la Corporación. En estas radios en la década de los 60 y 70 del siglo pasado, se transmitían novelas y programas dramatizados, algunas de ellas todavía presente en la memoria de sus habitantes: "Escuchábamos las novelas, Pancho Madrigal, Kalimán, Cumbres Borrascosas, ya me imaginaba yo los cascos de los caballos". (Dora, 2014).

Las prácticas deportivas, como el beisbol, era de los más populares en la Comarca, la mayoría de los jóvenes y adultos lo practicaban. Los entrevistados recuerdan uno de los equipos que se formó en San Antonio, "Los Piratas". Las jóvenes practicaban el "kickbol", deporte que similar al beisbol, la diferencia estriba que en lugar de usar bates, guantes o máscaras, se utiliza una pelota parecida aldel fútbol, lanzándose desde un diamante al estilo del boliche y una persona lo patea. Este último deporte, pudo haber sido incorporado a la comunidad, producto de las experiencias recreativas adquiridas en los institutos públicos de secundaria, donde asistían algunas en la década de los 70 .

Las bodas y cumpleaños eran grandes acontecimientos en San Antonio. A Partir de la década de los 60 las fiestas eran amenizadas con tocadiscos o rockonolas, las cuales contenían discos de acetato. Al no existir luz eléctrica, estos aparatos funcionaban con energía generad por pequeñas plantas eléctricas portátiles. Las entrevistadas de mayor edad, recuerdan con nostalgia, canciones como:"Hayluto en mi alma", "Amor de estudiante"; grupos musicales nicaragüenses como "Los Panzers"; grupos de música pops como Los Bee Gees y cantantes como Leo Dan, escuchados también por la radio.

Como se ha mencionado anteriormente, el cine era otra fuente de convergencia y unión entre los miembros de la Comarca, y de manera particular, los fines de semana, cuando se presentaban películas mexicanas. Entre las películas más recordadas por las entrevistadas de mayor edad, están las de "Cantinflas". Pedro Infante entro otras. En la Comarca se recuerdan dos Cantinas, y un billar, sitios también

Alejandra Rebecca Pérez López de socialización, estigmatizados ambos por algunas familias que los veían como un sitio poco sano. Las propietarias de las cantinas, era doña Alejandra Ayerdis y Juana Rivas. El billar pertenecía a don Will Ordeñana. Este último cerró a raíz del asesinato del ciudadano Salvador Castañeda, vecino de la Comarca. Según cuentan las entrevistas se debió a rencillas entre familias: “...Llevaban traídos porque ya un Castañeda había matado a un Escobar eso fue en el 1974..."(López, 2014).

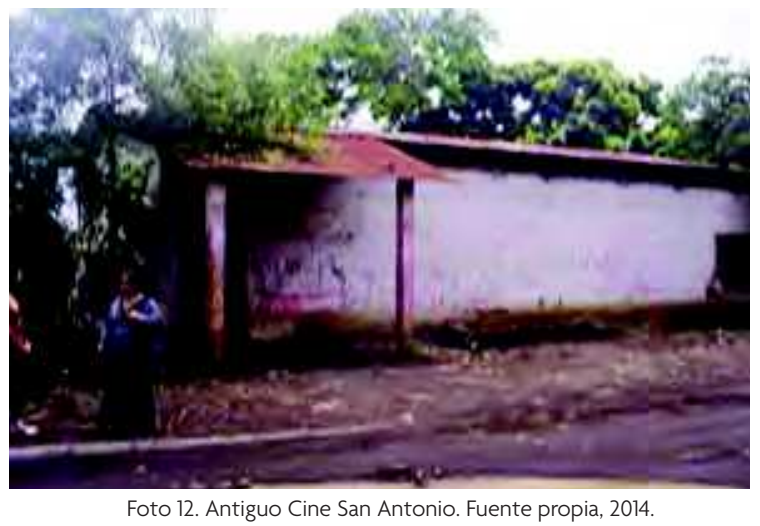

\section{Relación con las comarcas vecinas}

Los habitantes de San Antonio han tenido una relación conflictiva con algunos habitantes de las comarcas vecinas, San Antonio y Gaspar García Laviana, debido a prejuicios derivados de las formas en que los habitantes de la Comarca adquirieron las tierras que habitan. Uno de los factores que pueda influir en esta tensa relación tenga como base el hecho que la Comarca está conformada por pobladores de menores recursos que la de sus vecinos.

Los habitantes de San Antonio consideran que la actitud de las comarcas vecinas obedece a actitudes discriminatorias, porque no existe fundamento para cuestionar la legalidad o no de la adquisición de los solares y/o propiedades. Los entrevistados afirman que los terrenos fueron donadas por el Ministro Cruz Porras:“...Nosotros los habitantes de la comarca sufrimos discriminación [de los habitantes de las comarcas vecinas], porque nos regalaron esta tierra. Yo no me la robe y [el ] dolor que tienen porque aquí nohay delincuencia, hay [un adquisición] limpia... "(Sotelo, 2014).

\section{Conclusiones}

Desde sus inicios la comarca San Antonio, ha enfrentadograndes retos debido a una serie de factores, geográficos, políticos y de marginación y pobreza. El contexto en el cual surge como Las comarcas también tienen historia, San Antonio Sur... 
comunidad, pudo haber sido el menos feliz, desde el punto de vista histórico, debido a situaciones naturales, y la particularidad que siguieron al asentamiento de familias, algunas de ellas vinculadas al régimen dictatorial. Aun con ese telón trágico, la comarca posee una riqueza cultural y belleza natural que la caracteriza y diferencia de otras zonas aledañas con un alto índice de urbanización.

San Antonio Sur es un espacio donde sus habitantes mantienen viva en su memoria colectiva las raíces de la Comarca. La identidad de sus habitantes es una construcción dinámica, la cual se nutre de los recuerdos siempre presente en los adultos, quienes en ratos libres rememoran con sus hijos, por medio de tertulias $\mathrm{y} / \mathrm{o}$ conversaciones familiares.

En la comarca se mezcla la vida urbana con la rural, dado que ella es una especie de archipiélago, donde las casas modestas con patios amplios, cría de animales domésticos, pequeños huertos, y otras formas de vida rural, sobresalen ante construcciones modernas o negocios establecidos; calles asfaltadas y una infraestructura comunicacional propia de las ciudades.

56 Como factores que han afectado el desarrollo de la comarca, puede mencionarse la falta de vías de acceso adecuadas. Por otro lado, los gobiernos no han creado una infraestructura educativa adecuada para los habitantes de las casi 400 familias que habitan la Comarca.

Por último, es importante destacar que el nivel de vida de sus habitantes ha mejorado de manera ostensible en los últimos años. Las viviendas precarias han ido despareciendo y existen nuevos sistemas de transporte (moto taxi).Se observa en la comarca una actitud positiva en un futuro mejor para sus habitantes.

\section{Referencias bibliográficas}

Benadiba, L. (2007). Historia oral, relatos y memorias. Buenos Aires.

Gutierres, C. A. (2003). Entorno socioeconomico de Mexico . Mexico: Mexico.

Camarero. M, Morales T, y Necoechea G (1994) Re construyendo nuestro pasado: técnicas de historia oral. lera Edición impreso en México Halbwachs, M. (2011) La memoria colectiva. Buenos Aires: Miño y Dávila Editores.

\section{Entrevistas en audio}

Anónimo. (2014).[entrevista con Anonimo], grabación en audio.

Sotelo A. (2014) [Entrevista con Dora Sotelo, maestra particular de la Comarca San Antonio] grabación en audio.

Lopez, R. (2014). [Entrevista con Ruth López habitante de la Comarca San Antonio Sur] grabación en audio.

Obando, J. (2014). [entrevista con Judith Obando estudiante de Historia] grabación en audio.

Silva, C. (2014). [entrevista con Catalina Silva habitante de la Comarca San Antonio Sur] grabación en audio.

Lopez, A.(2014). [entrevista con Angelica Lopez Habitante de la Comarca San Antonio Sur] grabación en audio.

Fonseca, G. (2014). [Entrevista en audio con Gustavo Fonseca habitante de la comarca San Antonio Sur]

María Emelina Angulo, (2012) [María Emelina Angulo Habitante de la Comarca San Antonio Sur] 


\section{Anexos}

Relación de entrevistas grabadas

\begin{tabular}{|c|c|c|c|c|c|c|}
\hline $\begin{array}{l}\text { Tipo de } \\
\text { entrevista }\end{array}$ & $\begin{array}{l}\text { Nombre y } \\
\text { apellido }\end{array}$ & $\begin{array}{l}\text { Fechay } \\
\text { hora }\end{array}$ & Lugar & Ofieio & Eded & Criterio de la entrevista \\
\hline individual & Dara Averdis & $\begin{array}{c}15 / 09 / 2014 \\
11: 30 \mathrm{am}\end{array}$ & $\begin{array}{c}\text { Casa de } \\
\text { habitacion } \\
\text { Contiguo } \\
\text { escuela püblica } \\
\text { de San Antonia } \\
\text { Sur }\end{array}$ & $\begin{array}{c}\text { Maestra } \\
\text { particular de } \\
\text { San Antonio } \\
\text { Sur San } \\
\text { Antonio Sur }\end{array}$ & 54 ahos & $\begin{array}{l}\text { Personaje muy popular de la } \\
\text { comarca, Reconocida por el } \\
\text { goblerno por su labor } \\
\text { edueadora }\end{array}$ \\
\hline individual & Ruth López & $\begin{array}{c}15 / 09 / 2014 \\
06: 00 \mathrm{pm}\end{array}$ & $\begin{array}{c}\text { Casa de } \\
\text { habitación. San } \\
\text { Antonio Sur, } \\
\text { 5ta rampa }\end{array}$ & Ama de casa & 51 anos & $\begin{array}{c}\text { Habitante muy reconocida en } \\
\text { San Antonio, contacto } \\
\text { principal. }\end{array}$ \\
\hline Individual & Catalinasitua & $\begin{array}{c}15 / 09 / 2014 \\
9: 17 \mathrm{am}\end{array}$ & $\begin{array}{c}\text { Casa de } \\
\text { habitación. } \\
\text { Entrada a San } \\
\text { Antonio }\end{array}$ & Comerclante & 87 anos & $\begin{array}{l}\text { Madre de la concejal Dina } \\
\text { Contreras. }\end{array}$ \\
\hline Individual & $\begin{array}{l}\text { Iudith } \\
\text { Obando }\end{array}$ & $\begin{array}{l}25 / 09 / 2014 \\
11: 45 \mathrm{am}\end{array}$ & $\begin{array}{l}\text { (UNAN. } \\
\text { Managua) }\end{array}$ & $\begin{array}{l}\text { Estudiante de } \\
\text { Historia } \\
\text { (UNAN- } \\
\text { Managua) }\end{array}$ & 22 anos & $\begin{array}{c}\text { Actualmente realiza } \\
\text { investigacianes sabre el Ba. } \\
\text { Altagracla }\end{array}$ \\
\hline Colectiva & $\begin{array}{l}\text { Angélica } \\
\text { López }\end{array}$ & $\begin{array}{c}25 / 09 / 2014 \\
3: 26 \mathrm{pm}\end{array}$ & $\begin{array}{c}\text { Casa de } \\
\text { habitación. San } \\
\text { Antonio Sur, } \\
\text { Sta rampa. }\end{array}$ & Ama de casa & 57 anos & $\begin{array}{c}\text { Habitante conocedara de la } \\
\text { histaria de la Comarca }\end{array}$ \\
\hline Colectiva & Anónimo & $\begin{array}{c}25 / 09 / 2024 \\
10: 00 \mathrm{am}\end{array}$ & $\begin{array}{c}\text { Casa de } \\
\text { habitación. San } \\
\text { Antonio }\end{array}$ & Maestra & $\cdots$ & $\Leftrightarrow+\infty$ \\
\hline
\end{tabular}

